\title{
Detection of Multiple Dengue Infections by Rt-qPCR in West Sumatera, Indonesia
}

\author{
Almurdi Almurdi ${ }^{1 *}$, Ellyza Nasrul ${ }^{1}$, Efrida Efrida ${ }^{1}$, Nuzulia Irawati $^{2}$ \\ ${ }^{1}$ Department of Clinical Pathology, Faculty of Medicine, Andalas University, Indonesia; ${ }^{2}$ Department of Parasitology, Faculty of \\ Medicine, Andalas University, Indonesia
}

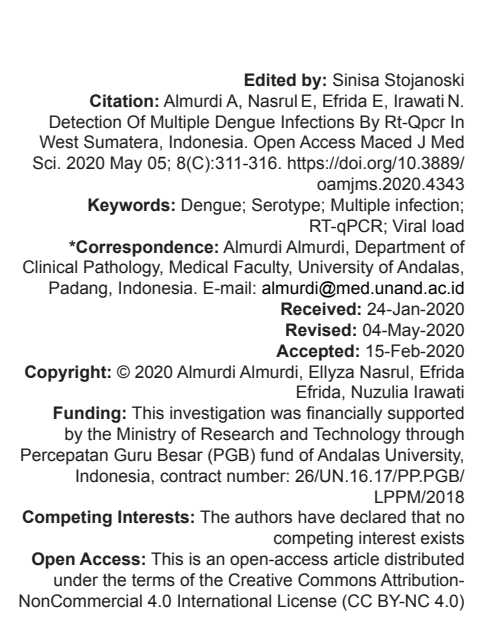

\section{Abstract}

BACKGROUND: Dengue is a disease caused by four distinct serotypes of dengue virus (DENV 1-4). DENV serotype differs from one another by $25-40 \%$ at the amino acid level. The detection of serotype is very important due to the fact that in secondary infection with heterologous serotype often leads to life threatening, dengue hemorrhagic fever (DHF)/dengue shock syndrome (DSS); likewise, an infection caused by two serotypes or more in one individual can contribute to the severity of infection.

AIMS: The aims of the study were to detect the multiple dengue serotypes infection by quantitative reverse transcription polymerase chain reaction (Q-RT-PCR) and to determine the viral load in dengue infection.

MATERIALS AND METHODS: This study applied the molecular examination for determining the serotype and viral load of DENV. The data were analyzed using Student's t-test.

RESULTS: A total of 119 samples, 91 samples showed positive dengue infection after amplification. The multiple dengue infection was found in 47 samples and 44 samples with single infection. There was a significant difference between the number of viral load DENV-2 and DENV-1 infection $(p=0.000)$.

CONCLUSION: Two or more serotypes of dengue were found to infect a patient in West Sumatra. DENV-2 serotype was found predominantly in West Sumatra $(n=36,39.56 \%)$ in patients with single infection. The molecular detection of dengue RNA by RT-PCR is a sensitive, rapid, and simple method. The RT-PCR method can detect the multiple dengue infection in clinical samples.

\section{Introduction}

Dengue is a disease caused by four distinct serotypes of dengue virus (DENV 1-4). Dengue virus is an Ss-RNA virus, spherical particles with diameter of $50 \mathrm{~nm}$, belongs to the genus Flavivirus. The RNA genome of the virus is approximately $10.7 \mathrm{~kb}$ in length and encodes three structural $(\mathrm{C}, \mathrm{prM} / \mathrm{M}$, and $\mathrm{E})$ and seven non-structural (NS1, NS2A, NS2B, NS3, NS4A, NS4B, and NS5) proteins. They are antigenically diverse and only share about $60-75 \%$ identity at the amino acid level [1], [2], [3], [4].

Dengue virus is a mosquito-transmitted virus that infects millions humans each year [5]. This virus is transmitted to humans through the bites of infected Aedes mosquitoes primarily by Aedes aegypti and Aedes albopictus mosquitoes [6], [7]. Infected human is the main carrier and spreader of DENV, the virus then is transmitted to uninfected mosquitoes for subsequent transmission. Dengue fever is one of the major human infectious diseases in tropical and subtropical areas [8], [9], [10].

Indonesia is one of the largest countries in the region of endemic dengue. Indonesia has experienced epidemic cycles of dengue since the first introduction in 1968. The frequent dengue cases are often followed by increasing number of infection which affected almost all provinces in Indonesia. Every year occurs the outbreak of dengue in several provinces with case fatality rate around $0.86-0.89 \%$. Concurrent infection of multiple dengue serotypes has been reported in Indonesia, Mexico, and Puerto Rico as well as other countries [10], [11], [12], [13]. In 2010, Indonesia became the first ranked country in the Association of Southeast Asian Nations by the highest number cases of dengue hemorrhagic fever (DHF) and was predicated as a hyperendemic area because multiple serotypes were found in blood circulation of dengue patients [11], [14].

In dengue infection, detection of serotype is very important because the fact that in secondary infection with heterologous serotype often leads to life threatening, DHF and DSS [14]. Infection with one serotype does not confer cross-protection against the other serotypes, instead can cause a severe form of infection. Infection by one serotype provides the recovered patient with a lifelong immunity against specific serotype [15], [16]. Likewise, an infection caused by two serotypes or more in a single individual can contribute to the severity of infection, then 
serotyping becomes very important in the management of patients with dengue virus infection [11].

At present, the previous methods that are used to diagnose DENV infection are virus isolation, detection of dengue specific antibodies and antigens, and amplification of viral RNA. To date, the molecular detection of dengue RNA by RT-PCR offers a sensitive, rapid, and simple. Several real-time PCR-based methods for the detection of DENV have been reported, these assays have targeted the 3' UTR, NS5, capsid, and the envelope gene sequences. The increased prevalence of dengue infection in recent decades and high mortality caused by DHF and DSS need for more sensitive and specific diagnostic assays such as RT-PCR for the detection and typing of DENV [4], [8], [16].

During the acute phase of primary infection, RNA can usually be detected using various platforms PCR. Although PCR is more sensitive during secondary infection, the window of viremia is very short. The level of DENV viremia in early infection might be predictive for the development of severe disease later. It has been suggested that a viral titer $10^{6}-10^{8}$ infectious units $/ \mathrm{mL}$ during the febrile phase is predictive for the development of severe disease [3]. The high dengue viremia titer was associated with the increasing of disease severity. Peak viral titers were 100-1000-fold higher in patients with DSS than those with DHF in dengue infection. Although cases of DHF/DSS have been reported in individual without prior exposure to DENV, most of cases occurred in patients who have been sequentially infected by at least two DENV serotypes [17], [18]. The aims of this study were to detect of multiple dengue serotype infection by qRT-PCR and to determine the viral load in dengue infection patients.

\section{Materials and Methods}

\section{Location and population of study}

A total of 119 samples were used in this study, samples were collected from five clinical laboratories at public hospitals in West Sumatera (Dr. M. Djamil General Hospital, Padang; Dr. Ahmad Muchtar Regional Public Hospital, Bukit Tinggi; Regional Public Hospital, Padang Panjang, Regional Public Hospital, Pariaman, and Regional Public Hospital, Painan). This study was conducted on January 2018 to October 2019. This study used purposive sampling technique to investigate the multiple dengue infection in all subjects. All samples were collected within the first 5 days of illness. Samples were previously screened using NS1 and/or IgM and IgG anti-dengue detection. Molecular analysis was conducted in Biomedical Laboratory, Faculty of Medicine, Andalas University, Padang.

\section{Preparation of samples}

Blood samples were collected from each patient who visited clinical laboratory to conduct serologic dengue test and whole blood examination (hematology analyzer). Blood was taken using an aseptic procedure from the mediana cubiti vein by trained personnel, using $3 \mathrm{cc}$ syringe. Serum was separated and stored at $-80^{\circ} \mathrm{C}$. All subjects were briefed on the study including the objectives, risks, and benefits of the study and inform consent was conducted through viva voce. The study was approved by Ethics Committee of Medical Faculty, Andalas University, Padang, Indonesia, No: 268/KEP/FK/2019.

\section{Viral RNA extraction and cDNA synthesis}

Serum of patient's with dengue fever was collected from blood and followed by RNA viral extraction. RNA viral was extracted from $140 \mathrm{uL}$ serum samples using QIAamp Viral RNA Mini Kits (Qiagen, Germany) according to the manufacturer's instructions and then stored at $-80^{\circ} \mathrm{C}$ until further analysis.

The extracted RNA template was denatured at $65^{\circ} \mathrm{C}$ for $10 \mathrm{~min}$ with DNAse Amp Grade (Invitrogen, USA) and then conversely transcribed to cDNA in 20 uL reaction mixture comprising 11 uL RNA, 4 uL 5x trans Amp buffer, $1 \mathrm{uL}$ reverse transcriptase, and 4 uLDNAse/RNAse free water (Bioline cat no. Bio 65053). The reaction was allowed to proceed at $25^{\circ} \mathrm{C}$ for $5 \mathrm{~min}$, $46^{\circ} \mathrm{C}$ for $20 \mathrm{~min}$, and followed by enzyme inactivation at $95^{\circ} \mathrm{C}$ for $1 \mathrm{~min}$.

\section{Detection of DENV RNA by $q R T-P C R$}

The RT-PCR was performed using nested qPCR method, the capsid gene was amplified by PCR with first round of PCR used outer primer Dengue_F (5' to 3'): GAGAAACCGCGTGTCAAC and Dengue R: TCCTGCTTGCTGACTATCATG; furthermore, the second round of PCR used four specific primers DENV-1 (5' to 3'): TTCTTTCTTGAAACTCCGTAGC, DENV-2 (5' to 3'): GCGGGATTGTTAGGAAACGA, DENV-3 (5' to 3'): CTTTTTCCGTCTGTTGATAATGC, and DENV-4 (5' to 3'): GACCTATCTCCTTCCTGAATCCAA. The primers were derived from positive screening of DENV. The DENV was amplified and sequenced to obtain the whole sequences. Then, Basic Local Alignment Search Tool was needed to confirm the result of isolation. The primer was designed by Primer3 (version 0.4.0). The size of the nested PCR product was 205 bp for DENV1, $125 \mathrm{bp}$ for DENV-2, $244 \mathrm{bp}$ for DENV-3, and 212 bp for DENV-4. DNA amplification was performed with reaction conditions as follows: Denaturation at $95^{\circ} \mathrm{C}$ for $30 \mathrm{~s}$ and five cycles of denaturation at $95^{\circ} \mathrm{C}$ for 5 $\mathrm{s}$ and annealing at $65^{\circ} \mathrm{C}$ for $5 \mathrm{~s}$, and then 11 cycles touchdown $(-1 \mathrm{C} /$ cycle $)$ denaturation at $95^{\circ} \mathrm{C} 5 \mathrm{~s}$ and annealing at $65^{\circ} \mathrm{C}$ to $55^{\circ} \mathrm{C}$ for $5 \mathrm{~s}$. Furthermore, 19 
cycles of denaturation at $95^{\circ} \mathrm{C}$ for $5 \mathrm{~s}$, annealing at $55^{\circ} \mathrm{C}$ for $5 \mathrm{~s}$, and the melt curved at $65^{\circ}-95^{\circ}$ for $5 \mathrm{~s}$ (every $5 \mathrm{~s}$ the temperatures raised $0.5^{\circ} \mathrm{C}$ (Figure 1). For first round of PCR, $1 \mathrm{uL}$ of cDNA added to $5 \mathrm{uL}$ EvaGreen (Biorad, USA), 0.5 uL primer Dengue-F, 0.5 uL primer Dengue-R, and $3 \mathrm{uL}$ of nuclease-free water in $10 \mathrm{uL}$ reaction mixture. External PCR was followed by the second round of nested PCR using the primer Dengue- $F$ and four serotype-specific primers (DEN-1, DENV-2, DENV-3, and DENV-4). The amplified product of the external PCR was diluted in ratio of 1:100. The $10 \mathrm{uL}$ of nested PCR mixture was prepared by adding $1 \mathrm{uL}$ of diluted external PCR product to $5 \mathrm{uL}$ EvaGreen (Biorad, USA), $0.5 \mathrm{uL}$ of primer Dengue-F, $0.5 \mathrm{uL}$ of each primers DENV-1 or DENV-2, or DENV-3, or DENV4 , and 3 uL of nuclease-free water.

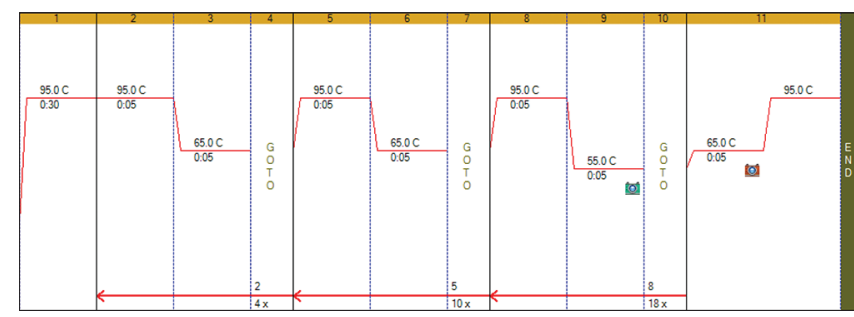

Figure 1. The profile of touchdown $q-P C R$

\section{Statistical analysis}

Statistical analysis was performed using SPSS 15.0. Pooled data were presented as the average value. Data were compared using Student's t-test, $p<$ 0.05 was considered statistically significant.

\section{Results}

\section{Sumatra}

\section{The serotype of dengue infection in West}

In this study, 119 samples were obtained from serologic reactive patients, 91 samples $(76.47 \%)$ showed positive dengue infection after PCR amplification, and 28 samples (23.36\%) were negative. Positive results consist of multiple dengue infection 47 samples of 91 positive samples (51.64\%) and 44 samples with single serotype dengue infection (48.33\%). From 47 samples with multiple serotype dengue infection, 30 samples $(32.97 \%)$ were infected by DENV-1 and DENV-2, 13 samples (14.28\%) were infected by DENV-1, DENV-2, and DENV-4, three samples (3.30\%) were infected by DENV-2 and DENV4 , and one sample was $(1.09 \%)$ infected by DENV-2 and DENV-3. The sample with single serotype of dengue virus infection was five samples with DENV-1 (5.49\%), 36 samples with DENV-2 (39.56\%), one sample with DENV-3 $(1.09 \%)$, and two samples with DENV-4 (2.19\%) (Table 1).
Table 1: Frequency of dengue serotype

\begin{tabular}{lll}
\hline Serotype & Number of samples & Percentage (\%) \\
\hline Multiple DENV: & & \\
DENV-1 and DENV-2 & 30 & 32.97 \\
DENV-1, DENV-2, and DENV-4 & 13 & 14.28 \\
DENV-2 and DENV-4 & 3 & 3.30 \\
DENV-2 and DENV-3 & 1 & 1.09 \\
Total & 47 & 51.64 \\
Single DENV: & & \\
DENV-1 & 5 & 5.49 \\
DENV-2 & 36 & 39.56 \\
DENV-3 & 1 & 1.09 \\
DENV-4 & 2 & 2.19 \\
Total & 44 & 48.33 \\
\hline
\end{tabular}

\section{Sumatra}

\section{Viral load of dengue infection in West}

The viral load count showed that DENV-2 $(8.01 \pm 0.79) \mathrm{log} / \mathrm{mL}$ was the highest serotype number than DENV-4 and DENV-1 (7.89 \pm 1.01 and $7.57 \pm$ 0.61 , respectively). Data of viral load for DENV-3 were not analyzed because only two samples were positive result. The number of viral load for DENV-2 and DENV-1 showed significant difference $(p<0.05)$, while DENV-4 was not significantly different. Based on gender, this study showed that most infected patients were male of 54 samples $(59.34 \%$ ) and female of 37 samples (40.66\%) (Table 2).

Table 2: The average of several parameters on dengue patients

\begin{tabular}{llllll}
\hline Parameter & $\mathrm{n}(\%)$ & Mean (SD) & Min. & Max. & p-value \\
\hline Gender & & & & & \\
$\quad$ Male & $54(59.34)$ & & & & \\
$\quad$ Female & $37(40.66)$ & & & & \\
Hematology parameters & & $61,000 \pm 30,490$ & 15,000 & 132,000 & \\
$\quad$ Platelet (/uL) & & $39.62 \pm 5.76$ & 21 & 49 & \\
$\quad$ Hematocrit (\%) & & $4364.71 \pm 1483.05$ & 2400 & 8400 & \\
$\quad$ Leukocyte (/uL) & & & & & \\
Viral load (log mL-1) & & $8.01 \pm 0.79$ & 6.93 & 11.59 & .000 \\
$\quad$ DENV-2 & & $7.57 \pm 0.61$ & 7.00 & 11.00 & .138 \\
DENV-1 & $7.89 \pm 1.01$ & 7.14 & 11.15 & \\
DENV-4 & & & & & \\
\hline
\end{tabular}

The results showed that hematology parameter such as thrombocyte was to decrease with the average 61,000 per $u L \pm 30,490$. Eleven samples $(12.1 \%)$ with the number of thrombocyte were above 100.000/uL but $<150.000 /$ uL. The average of leukocyte count also decreased 4364.71/uL \pm 1483 , and hematocrit average was $39.62 \% \pm 5.76$ (hematocrit count was less than normal which found in 12 samples) $(13.2 \%)$.

The curves of melt peak in Figure 2 showed specific result for DENV1, DENV2, DENV3, and DENV4. All serotypes showed one peak result with uniform melt peak temperature. The optimation temperature of the fourth serotypes for annealing was at $55^{\circ} \mathrm{C}$ and the melt curved at $65^{\circ-} 95^{\circ} \mathrm{C}$.

\section{Discussion}

The dengue infection in West Sumatra was high, 91 samples $(76.47 \%)$ showed positive result of 119 samples. The serotype of dengue infection showed 


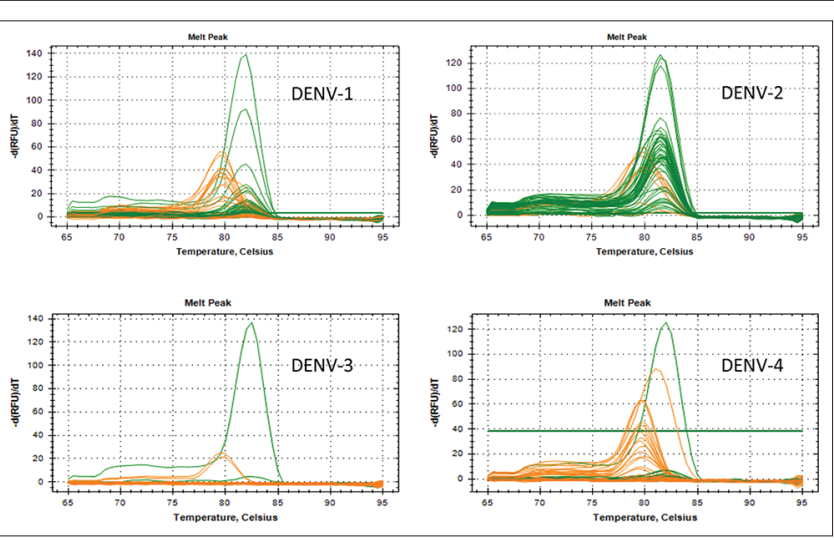

Figure 2: Melting curves of DENV-1 to DENV-4 real-time RT-PCR products from patients who infected by dengue virus

that DENV-2 was found predominantly in West Sumatra $(\mathrm{n}=36,39.56 \%)$ in patients with single infection. Whereas, DENV1 and DENV2 dominated in multiple infection. In parameter of gender, it was found that male was slightly more affected by dengue virus than female.

In Indonesia, DENV-2 serotype dominated, followed by DEN-3 in 2003-2005. In 2008-2009, Surabaya was also dominated by DENV-2. Most of isolated DENV in Semarang was DENV-1, while the most predominant serotype in Purwokerto was DENV-3 and other cities such as Jakarta, Palembang, and Bali in 2015, whereas DENV-4 was found in Bandung. These findings described that the differences of DENV serotype were found in different cities. Thus, it demonstrated the spatial and temporal dynamics of DENV distribution in Indonesia [11], [12].

Over the past few decades, the number of people infected with DENV has risen steadily due to the expansion of urban population, global travel and commerce, and paucity of mosquito control program [5].

There are many complex factors that may have contributed to the increase in dengue cases such as the increasing number of people migration, population growth, poverty, health inequality, and climate warming which have increased mosquito density and expanded the geographic distribution and seasonal distribution of Aedes mosquitoes [1]. Hot and wet environmental conditions increase the number of vector mosquito. Controlling of main vector is essential to prevent epidemics caused by the virus.

The number of multiple dengue case found has increased. In 2010, Indonesia became the first ranked country in with the highest number cases of DHF and hyperendemic predicate [11]. Dengue hyperendemic regions refer to locations with two or more simultaneously circulating dengue serotypes [19]. In many dengue hyperendemic countries, multiple DENV of all four serotypes are cocirculate [20]. Detection of dengue virus serotypes is very important because secondary infection with a different serotype may impact more severe. Likewise, an infection caused by two serotypes or more in a single individual can contribute to the severity of the infection. Then, serotyping is very important in the management of patients with dengue virus infection [11].

The dramatic increase in global dengue burden has promoted social interest in improving dengue diagnosis. The current methods for confirming dengue in the laboratory are serology test, viral isolation, and nucleotide detection [21]. Early diagnosis is important for the clinical management of dengue and may prevent unsatisfactory outcomes. Dengue virus and dengue viral products are detected in serum at the early illness period; consequently, the sensitivity of dengue diagnostic methods as real-time PCR, virus isolation, or NS1 detection is higher at the $1^{\text {st }}$ day of illness [22].

Infection by one serotype provides the recovered patient with a lifelong immunity against the specific serotype. The previous studies have showed that if a recovered patient is infected with another serotype, the preexisting heterologous antibodies from previous infection complicate with novel serotype of dengue virus, but the pathogenesis not neutralized by the immune system. Instead, the complex of antigen antibody seems to facilitate the virus entry to the cells, which can cause an uncontrolled virus replication, higher peak viral titers, and more severe dengue disease [19].

The infection begins with an infected mosquito injects dengue virus, disseminates and infects multiple lymphoid and non-lymphoid tissues. A viremia is presumably representing the underlying severity of tissue infection. Viremia peaks shortly after fever onset and then becomes flat for 1-2 days before gradually declining [23]. Melt curve analyses is often used to confirm the fidelity of the reaction. Viremia was found to be higher in the initial days of illness decreasing gradually during the later stages of the infection [16]. Circulation of DENV remains detectable in blood during febrile period and is rapidly cleared with appearance of specific antibody [18]. In routine assay, two steps method with a RT-PCR followed by a nested PCR is used for serotyping of dengue viruses [14].

In this study, high multiple infection was detected in West Sumatra $(51.64 \%)$ because every sample was amplified for 5 times, amplified with outer primer and with specific serotype (DENV1, DENV2, DENV3, and DENV4). Technically, this procedure could prevent mismatch between primer and target, as it occurs in PCR multiplex. Peripheral blood parameters change during the course of illness. Dengue fever is characterized by leukopenia $<5000 / u L$, rising hematocrit up to $5-10 \%$, and thrombocytopenia $<150.000 /$ LL. In dengue hemorrhagic fever, peripheral blood parameters characterized by thrombocytopenia $<100.000 /$ L and hematocrit rise $>20 \%$. Thrombocyte contributes to increase vascular permeability by inflammation, depends on releasing of IL-1 $\square$. A rapid decrease in thrombocyte count, concomitant with a rising of hematocrit, leads the progression of plasma leakage[24]. As thrombocytopenia implicates higher 
risk for menorrhagia [25]. Thrombocytopenia occurs commonly in laboratory-confirmed dengue cases on days 2-7. A patient with dengue had more severe thrombocytopenia on days 4-7, and the platelet count reached the lowest number on day 5 [26]. The pathogenesis of thrombocytopenia and leukopenia is suggested that dengue virus induced bone marrow suppression and depressed platelet and leukocyte synthesis and resulted in thrombocytopenia and leukopenia [7], [17].

\section{Conclusion}

Two or more serotypes of dengue were found to infect a patient in West Sumatra. DENV-2 serotype was found predominantly in West Sumatra $(n=36$, $39.56 \%$ ) in patients with single infection. The molecular detection of dengue RNA by RT-PCR is a sensitive, rapid, and simple method. The RT-PCR method can detect the multiple dengue infection in clinical samples. The level of DENV viremia in early infection might be predictive for the development of severe disease later that can be beneficial for the management of patients with dengue virus infection.

\section{Acknowledgment}

The authors thank to The Ministry of Research and Technology through Percepatan Guru Besar (PGB) fund of Andalas University for financing of fundamental research in 2018 with contract number: 26/UN.16.17/ PP.PGB/LPPM/2018.

\section{References}

1. Sun J, Lu L, Wu H, Yang J, Xu L, Sang S, et al. Epidemiological trends of dengue in mainland China, 2005-2015. Int J Infect Dis. 2017;57:86-91. https://doi.org/10.1016/j.jijd.2017.02.007 PMid:28214563

2. Vannice KS, Durbin A, Hombach J. Status of vaccine research and development of vaccines for dengue. Vaccine. 2016;34(26):2934-8. https://doi.org/10.1016/j. vaccine.2015.12.073

PMid:26973072

3. Martina BE. Dengue pathogenesis: A disease driven by the host response. Sci Prog. 2014;97(Pt 3):197-214. PMid:25549406

4. Sasmono RT, Aryati A, Wardhani P, Yohan B, Trimarsanto H, Fahri $\mathrm{S}$, et al. Performance of simplexa dengue molecular assay compared to conventional and SYBR green RT-PCR for detection of dengue infection in Indonesia. PLoS One. 2014;9(8):e103815. https://doi.org/10.1371/journal.pone.0103815

PMid:25102066

5. Diamond MS, Pierson TC. Molecular insight into dengue virus pathogenesis and its implications for disease control. Cell. 2015;162(3):488-92. https://doi.org/10.1016/j.cell.2015.07.005 PMid:26232221

6. Jayanthi HK, Tulasi SK. Correlation study between platele count, leukocyte count, nonhemorrhagic complications, and duration of hospital stay in dengue fever with thrombocytopenia. J Fam Med Prim Care. 2016;5(1):120-3. https://doi org/10.4103/2249-4863.184635

PMid:27453855

7. Joshi AA, Gayathri BR, Yashica GR. The total leucocyte count: Its utility in dengue. Int J Adv Med. 2017;4(6):1621-6. https://doi. org/10.18203/2349-3933.ijam20175178

8. Bhatnagar J, Blau DM, Shieh WJ, Paddock CD, Drew C, Liu L, et al. Molecular detection and typing of dengue viruses from archived tissues of fatal cases by rt-PCR and sequencing: Diagnostic and epidemiologic implications. Am J Trop Med Hyg 2012;86(2):335-40. https://doi.org/10.4269/ajtmh.2012.11-0346 PMid:22302871

9. Momin A, Zarghoona W, Munsif A, Fareha H, Ahsan AS, Anam A, et al. Correlation of temperature with platelet count and total leukocyte count in dengue: Findings from a secondary data analysis. SOJ Microbiol Infect Dis. 2019;7(1):1-4

10. Lin $\mathrm{Y}, \mathrm{Ma} \mathrm{D}$, Wen S, Zeng F, Hong S, Li L, et al. Molecular characterization of the viral structural gene of the first dengue virus Type 1 outbreak in Xishuangbanna: A border area of China, Burma and Laos. Int J Infect Dis. 2019;79:152-61. https://doi. org/10.1101/423152

PMid:30528395

11. Ansori AN, Sucipto TH, Deka PT, Ahwanah NL, Churrotin S, Kotaki T, et al. Differences of universal and multiplex primer for detection of dengue virus from patients suspected dengue hemorrhagic fever (DHF) in Surabaya. Indones J Top Infect Dis. 2015;5(6):147-51. https://doi.org/10.20473/ijtid.v5i6.594

12. Kusmintarsih ES, Hayati RF, Turnip ON, Yohan B Suryaningsih S, Pratiknyo $\mathrm{H}$, et al. Molecular characterization of dengue viruses isolated from patients in central java, Indonesia. J Infect Public Health. 2018;11(5):617-25. https://doi. org/10.1016/j.jiph.2017.09.019

PMid:29056517

13. Candra A. Dengue hemorrhagic fever: Epidemiology, pathogenesis, and its transmission risk factors. Aspirator. 2010;2(2):110-9.

14. Saxena P, Dash PK, Santhosh SR, Shrivastava A, Parida M, Rao PL. Development and evaluation of one step single tube multiplexRT-PCR for rapid detection and typing of dengueviruses. Virol J. 2008;5:20. https://doi.org/10.1186/1743-422x-5-20 PMid:18234069

15. Anand AM, Sistla S, Dhodapkar R, Hamide A, Biswal N Srinivasan B. Evaluation of NS1 antigen detection for early diagnosis of dengue in a tertiary hospital in Southern India. J Clin Diagn Res. 2016;10(4):DC01-4. https://doi.org/10.7860/ jcdr/2016/15758.7562 PMid:27190798

16. Gurukumar KR, Priyadarshini D, Patil JA, Bhagat A, Singh A Shah PS, et al. Development of real time PCR for detection and quantitation of dengue viruses. Virol J. 2009;6:10. https://doi. org/10.1186/1743-422x-6-10

PMid:19166574

17. Lei HY, Yeh TM, Liu HS, Lin YS, Chen SH, Liu CC. Immunopathogenesis of dengue virus infection. J Biomed Sci. 2001;8(5):377-88. https://doi.org/10.1007/bf02255946 
PMid:11549879

18. Fagbami $A H$, Onoja $A B$. Dengue haemorrhagic fever: An emerging disease in Nigeria, West Africa. J Infect Public Health. 2018;11(6):757-62. https://doi.org/10.1016/j.jiph.2018.04.014 PMid:29706314

19. Abdel-Magid AF. Viral replication inhibitors may treat the dengue virus infections. ACS Med Chem Lett. 2016;8(1):14-6. https:// doi.org/10.1021/acsmedchemlett.6b00513

PMid:28105266

20. Teoh BT, Sam SS, Tan KK, Johari J, Danlami MB, Hooi PS, et al. Detection of dengue viruses using reverse transcriptionloop-mediated isothermal amplification. BMC Infect Dis. 2013;13:387. https://doi.org/10.1186/1471-2334-13-387 PMid:23964963

21. Zhang $\mathrm{H}$, Li W, Wang J, Peng $\mathrm{H}$, Che $\mathrm{X}$, Chen $\mathrm{X}$, et al. NS1based tests with diagnostic utility for confirming dengue infection: A meta-analysis. Int J Infect Dis. 2014;26:57-66. https://doi.org/10.1016/j.ijid.2014.02.002

\section{PMid:24984164}

22. Ferraz FO, Bomfim MR, Totola AH, Ávila TV, Cisalpino D Pessanha JE, et al. Evaluation of laboratory tests for dengue diagnosis in clinical specimens from consecutive patients with suspected dengue in Belo Horizonte, Brazil. J Clin Virol.
2013;58(1):41-6. https://doi.org/10.1016/j.jcv.2013.06.015 PMid:23871166.

23. Simmons CP,McPhersonK, Van VinhChau N, HoaiTamDT, Young $P$ Mackenzie J, et al. Recent advances in dengue pathogenesis and clinical management. Vaccine. 2015;33(50):7061-8. https://doi. org/10.1016/j.vaccine.2015.09.103

\section{PMid:26458808}

24. Ralapanawa $U$, Alawattegama AT, Gunrathne M. Sampath T, Kularatne SA, Thilak J. Value of peripheral blood count for dengue severity prediction. BMC Res Notes. 2008;11:400. https://doi.org/10.1186/s13104-018-3505-4

25. Kuo HJ, Lee IK, Liu JW. Analyses of clinical and laboratory characteristics of dengue adults at their hospital presentations based on the World Health Organization clinical-phase framework: Emphasizing risk of severe dengue in the elderly. J Microbiol Immunol Infect. 2018;51(6):740-8. https://doi. org/10.1016/j.jmii.2016.08.024

PMid:28734676

26. Chen $\mathrm{CH}$, Huang YC, Kuo KC, Li CC. Clinical features and dynamic ordinary laboratory tests differentiating dengue fever from other febrile illnesses in children. J Microbiol Immunol Infect. 2018;51(5):614-20. https://doi.org/10.1016/j.jmii.2016.08.018 PMid:28712817 